\title{
External expertise: the essential role of our Advisory Board
}

\author{
Robert W Schrier
}

The purpose of Nature Clinical Practice Nephrology is to provide practicing nephrologists with the most up-to-date information that has the potential to impact their clinical practice. On the basis of this aim, an international Advisory Board of leading experts from thirteen specialty areas of nephrology was appointed in 2005 (see Supplementary Table 1 online).

Members of the Advisory Board of Nature Clinical Practice Nephrology have quite a different role from that of Editorial Board members to other journals. Our Advisory Board members are an integral part of the editorial workflow, taking a hands-on approach to help realize the goals of this unique initiative. Advisory Board members-all of whom are highly aware of clinically relevant advances in their field-are in regular contact with our editorial staff, through which they provide suggestions to the Editor-in-Chief for topics to be covered in Reviews, Viewpoints and Case Studies. Board members approve highimpact original research papers for critique in our Practice Point section. Nomination of potential authors is also encouraged.

The responsiveness of our Advisory Board to date has been remarkable. Despite the many competing demands on their time, each makes a regular effort to share the benefit of their knowledge with our editorial staff, and via extension, with our readership. I am pleased with the quality of the initial monthly issues of Nature Clinical Practice Nephrology. I hope you are too, and can appreciate the value that the Advisory Board has added.

Advisory Board members recently took time out of their hectic conference schedules to attend our inaugural Board meeting during
Our Advisory

Board

members are

an integral part

of the editorial

workflow,

taking a

hands-on

approach to

help realize

the goals of

this unique

initiative

RW Schrier is Editorin-Chief of Nature

Clinical Practice

Nephrology.

\section{Competing interests}

The author declared he has no competing interests.

www.nature.com/clinicalpractice doi:10.1038/ncpneph0122
Renal Week 2005 in Philadelphia, PA, USA. Board members were updated on progress to date and plans for the future. Most importantly, it was a chance for editorial staff and the Editor-in-Chief to personally thank the Board for their invaluable contribution to the journal.

The Advisory Board is not the only source of expert knowledge on which we draw. Your expertise can also help to shape the journal. I encourage readers of Nature Clinical Practice Nephrology to make content-related recommendations, by contacting our editorial staff (via email to ncpneph@nature.com). Members of the International Society of Nephrology —of which the journal is an official publication-have already responded admirably in this regard. I hope that Society members and other subscribers will consider Nature Clinical Practice Nephrology to be their journal. In this way, we can ensure that the journal delivers what you, the readers, need.

Our small editorial team, based in the London offices of Nature Publishing Group, are the interface between the journal's Advisory Board, Editor-in-Chief, readers, authors and peer-reviewers. Suzanne Farley (Editor), Chloë Harman (Associate Editor) and Rachael Williams (Assistant Editor) commission, receive, edit and manage peer-review for all articles. During the several months in which I have worked with this team, I have come to understand why Nature Publishing Group is the leading biomedical publishing company in the world, and why Nature Clinical Practice Nephrology is sure to achieve its aims.

Supplementary information is available on the Nature Clinical Practice Nephrology website. 